\title{
CHALLENGES IN BUILDING UP LEARNER AUTONOMY IN RUSSIAN UNIVERSITIES
}

\author{
Chernova Oxana ${ }^{1}$, Litvinov Aleksandr ${ }^{2}$ Telezhko Irina ${ }^{3}$, Goloshumova Galina ${ }^{4}$ \\ ${ }^{1}$ Associate Prof., RUDN University, RUSSIA, \\ ${ }^{2}$ Associate Prof., RUDN University, RUSSIA; Full Prof., Moscow State University of Psychology \\ and Education, RUSSIA \\ ${ }^{3}$ Associate Prof., RUDN University, RUSSIA, \\ ${ }^{4}$ Full Prof., Moscow State Pedagogical University, RUSSIA
}

\begin{abstract}
The subject of the research is building up learner autonomy in vocationally-oriented language learning (VOLL) in Russian institutes of higher learning (IHL). In order to achieve this target, the authors made use of LMS MOODLE and worked out the stages that facilitate the process of learner autonomy formation. These include: the stage of self-diagnostics, cognitive and creative stage and that of evaluation and assessment.

Throughout the course the students learn to set goals, make priorities and independent decisions. They become more motivated and focused on the individualization of the learning process, get particularly interested in their future profession and life-long learning, master the learning material much better and faster, get accustomed to acquiring innovative techniques and methods, developing different groups of skills which contribute to success in becoming mature and autonomous learners.

The article analyzes the pedagogic conditions to be provided to help students get used to the new learning standards and environments. The authors believe that such pedagogic conditions as students' high value of autonomous learning, students' training to work independently in LMS MOODLE, teachers' ability and motivation to implement MOODLE will help facilitate language learning and take full advantage of the LMS. Special emphasis in the article is placed on the notion of learner autonomy and the necessary groups of skills to develop learner autonomy.

On the basis of the research which has been carried out for a number of years, the authors prove the fact that after completing the three above mentioned stages of the course, the $\mathrm{IHL}$ students tend to become more autonomous and independent learners who are better prepared and equipped to apply their new vision of the learning process to multiple areas of life.
\end{abstract}

Keywords: VOLL, LMS MOODLE, learner autonomy, ESP, translators, motivation, life-long learning

\section{INTRODUCTION}

This study has become a live issue due to the challenges for Russian educational policy in the 21st century: the need to adopt the paradigm of life-long learning as a result of the dynamic changes in every area of the Russian society, the new requirements for the graduates of the Institutes of Higher Learning (IHL) as individuals with high degree of autonomy. 
At present, the Russian system of higher education comprises a variety of formats, contents and ideas to contribute to humanization of education. Institutes of higher learning take different approaches in an attempt to resolve the issue of humanization of education by changing their curricula, and creating more flexible systems and forms of education aimed at developing learner autonomy, which is considered to be a priority for today's graduates. In the rapidly changing world, the ability to find, sort out, interpret and make use of the information obtained is of the highest value. This new emphasis stipulates the objectives and syllabus of the contemporary system of higher education: to educate an independent and autonomous learner able to accept responsibility for one's learning, work and life in an age of dynamic and changeable environment.

According to the Federal Law on Education in the Russian Federation, the duty of the educator is to "develop learners' cognitive activity, independence, initiative, creativity" [12], and "education is a result-oriented process of organizing the learners' activities to acquire knowledge, skills and competence, to gain experience in applying practical skills in everyday life and to build up learners' motivation to be involved in life-long learning" [12].

The State Standards of Higher Education of the Russian Federation stipulate the development of the following competences of the graduates: the ability to find, sort out, interpret, analyze, make a synthesis and use of the information obtained; to set goals and assign tasks independently and to make a choice of the best possible solution; to develop a self-development path for life; time-management.

Hence, the primary objective of the system of higher education is to help the learner create motivation with a view of his/her becoming a more independent and autonomous personality capable of changing society and himself/herself from the perspective of humanism.

In the current conditions, however, the level of learner autonomy of the graduates of Russian IHLs is at odds with the above mentioned requirements. With this context, one of the most topical issues is the introduction of new teaching techniques and methods to the development of learner autonomy taking into account local mentality, customs, traditions and beliefs deeply rooted in the society, review of traditional and, to a certain extent, out-of-date approaches to the learning process, creation and implementation of electronic information and educational environment.

Nowadays, foreign languages play an increasingly important role within the framework of qualitative structural changes in the Russian system of higher education. Modern society urgently needs secondary linguistic personalities rather than graduates who merely speak a foreign language to some degree. Recent years have seen a demand for translators of vocationally-oriented texts, caused by the process of globalization, improved cross-cultural relations, economic and political cooperation. To meet the demand, nonlinguistic institutes of higher learning are also engaged in training of such interpreters and translators. Obviously, since ESP students have less time to learn a foreign language in the curriculum compared to students of linguistic universities, they need to develop their autonomy and work persistently to become professionals in the field.

\section{METHODOLOGY}

The concept of learner autonomy has been in the focus of many scholars' attention both in the West $(\mathrm{H}$. Holec, D. Little, L. Lier, L. Dickinson, L. Mariani, G. Allport, and others) and in Russia (Y.N. Kulutkin, Zh.S. Anikina, N.F. Koryakovtcheva, I.V. Luksha, E.A. Nasonova, E.N. Solovova, T.Y. Ternovykh and others) since 1979 when Henri Holec, considered to be the 'father' of learner autonomy, wrote Autonomy and foreign language learning and defined learner autonomy as the "ability to take charge of one's own learning." [15] Holec stated that this ability "is not inborn but must be acquired either by 'natural' means or by formal learning, i.e. in a systematic, deliberate way", and pointed out that "to take charge of one's learning is to have $[\ldots . .$.$] the responsibility for all decisions concerning all aspects of this learning [\ldots . .] ".[15, p .3]$.

Many definitions have since been given to the term, depending on the writer, the context, and the level of debate educators have come to. This is because autonomy is seen either (or both) as a means or as a result in education. Defining autonomy is quite a complicated task because of its broad and abstract nature.

Little [24, p.435] writes that 'learner autonomy is the product of interdependence rather than independence', Littlewood introduces two levels of autonomy: 'proactive autonomy' and 'reactive autonomy.' Proactive autonomy regulates the direction of activity as well as the activity itself. Reactive autonomy regulates the activity once the direction has been set. It enables learners 'to organize their resources autonomously in order to reach their goal. It is this form of autonomy that stimulates the learner to do their learning' [25, p.75].

Nunan [29] states that 'Autonomous learners are able to self-determine the overall direction of their learning, become actively involved in the management of the learning process, exercise freedom of choice in relation to learning resources and activities.' Benson [4, p.47] defines autonomy 'as the capacity to take control of 
one's learning, largely because the contrast of 'control' appears to be more open to investigation that the constructs of 'charge' or 'responsibility'. Ur [42, p.19] regards autonomy as one of the three stages of the process of learning a skill, which is a three-stage course of instruction: verbalization, automation and autonomy, and explains that at the last stage learners continue to use the skill on their own. That is, they become 'autonomous'.

Y.N. Kulutkin considers that learner autonomy has both outer (learning strategies and activities) and inner (self-regulation) manifestations. The learner is both the subject and the object of control, and to some degree he becomes a teacher [23].

In Russian-English terminological reference book under the editorship of L.I. Kolesnikova autonomous learning is defined as complete independence, self-sufficiency of learners, when the teacher is almost excluded from the educational process and it's the student who determines objectives of his learning, the program and materials [19].

What most definitions imply is that learners become autonomous when they take full responsibility for the learning process, acknowledge the fact that success in learning depends on themselves rather than on other people, and develop the skills of reflection and analysis that enable them to plan, monitor and evaluate their learning. Autonomous learners become committed to self-management and apply their proactive approach to become motivated learners. Moreover, they can freely apply their knowledge and skills outside the immediate context of learning.

According to P.C. Candy, autonomous learners are methodical/disciplined, logical/analytical, reflective/selfaware, motivated/curious, flexible, interdependent/inter-personally competent, responsible/persistent, venturesome/creative, creative/have positive self-concept, independent/self-sufficient, skilled in seeking/retrieving information, knowledgeable about/skilled in learning, able to develop/use evaluation criteria [30].

Russian researchers, working at the concept of learner autonomy in the field of foreign language teaching, use the following terms: 1) Self-guided learning of foreign languages (A.E. Kapaeva, T.Y. Tambovkina); 2) Independent learning activity (K.V. Simonyan); 3) Learner self-regulation (Zh.S. Anikina, N.F. Koryakovtcheva, I.V. Luksha, E.A. Nasonova, E.N. Solovova, T.Y. Ternovykh); 4) Learner autonomy (D.A. Khodyakov, T.K. Tsvetkova, E.A. Tsyvkunova).

Analysis of the definitions of learner autonomy shows that the views of the researchers on the problem of determining autonomy can be divided into three groups: 1$)$ autonomy is the learner ability (H. Holec, D. Little, L. Mariani, J. Trim, P. Benson, N.F. Koryakovtseva, I.D. Trofimova, T.Y. Tambovkina,); 2) autonomy is not an ability or a need, but a learner's responsibility (L. Dickinson, E.N. Solovova); 3) autonomy as willingness to manage one's own learning process (O. Berg, D.A. Khodyakov).

We agree with the scholars who believe that learner autonomy is ability and by this ability we mean an individually expressed peculiarity of a person that allows one to perform certain activities. It should also be noted that in Russia as far as the methodology of teaching foreign languages is concerned, there is no consensus on terminology to denote this concept: according to N.F. Koryakovtseva and T.Y. Ternovykh, the terms "learner self-regulation" and "learner autonomy" are synonymous. T.Y. Tambovkina, I.D. Trofimova, O.V. Pustinina, Zh.S. Anikina prefer the term "learner self-regulation", E.A. Tsyvkunova, T.K. Tsvetkova "learner autonomy", and for E.V. Apanovich and N.D. Galskova the concepts "independent" and "autonomous" are identical and interchangeable.

The authors of this article share the point of view of those scholars [E.N. Solovova; K.E. Bezukladnikov], who believe that a learner autonomy cannot be equated to an independent learning activity, that the concept of "learner autonomy" is much broader than that of "independent learning activity", which necessitates its formation.

Taking into account the definitions of Western and Russian researchers in the field of learner autonomy, we define learner autonomy as an ability of an individual to consciously carry out his educational activities aimed at creating a personally significant educational product, self-reflex and adequately evaluate this product, accumulate positive experience, interact constructively and creatively with the educational environment and members of educational activities, taking responsibility for the process and product of this activity.

As far as components of learner autonomy are concerned, it can be noted that in studies devoted to the problem, the following components were identified: autonomy components of younger schoolchildren (L.D. Thong); components of autonomous learning activities in mastering a foreign language (E.A. Nasonova, Zh.S. Anikina); components of student's autonomy (G.I. Reznitskaya); parameters of the implementation of student autonomy in the educational process (E.V. Strelkova). 
Taking into account the directions of learner autonomy formation [21,22], we have identified the following components in the structure of learner autonomy: motivational, personal and competence-based. The motivational component includes the motives of autonomous learning activities: the need for self-education with the help of electronic educational resources; the need to master the skills, abilities and ways of autonomous activity.

The personal component includes: adequate self-esteem; mental properties that are the basis of learning activities; qualities and habits aimed at improving the effectiveness of independent activities (hard work, time management, etc.), mental personality characteristics (memory, attention, etc.) necessary for the effective fulfillment of autonomous work.

The competence-based component depends on the specialization of students and includes professionally significant skills.

In our study, we consider vocationally-oriented language learning (VOLL), i.e. the training of would-be engineers, who receive an additional qualification "Interpreter in the field of professional communication". With regard to these specialists, the competence-based component includes expertise, skills and abilities to set goals and independently find ways to achieve them, to plan and organize their autonomous work; to know the ways of working with information; to use e-learning resources for autonomous work, to speak a foreign language at least at level B1; to know techniques and methods of translation; to be able to switch between the source and target texts, to forecast, self-control, self-analyze and correct their activities.

In our study, we take into account the fact that learner autonomy has a multi-component structure, with four levels of formation of each autonomy component identified: A (creative) - high, B (productive) - above average, C (reproductive) - medium, D (factual) - low.

The authors have defined four groups of skills to be developed for students to become autonomous and independent. They are the following: 1) general skills (skills of goal-setting, planning, self-correction, selfcontrol, the ability to independently formulate transfer skills, to use technical training aids, reference and information skills); 2) subject-oriented skills (communicative skills by type of speech activity characterizing the level of knowledge of a foreign language as a means of communication; 3 ) intellectual (the ability to compare, summarize, analyze and systematize information, argue, draw conclusions, establish cause-effect relationships, classify, draw analogies, highlight the main ideas in the material); 4) psychological and characterological (perseverance, attention, good memory, high performance, perception, will, reflection, the ability to conduct self-monitoring and introspection, give an adequate self-assessment of their activities, be aware of their motives).

To help students develop their autonomy, the authors made use of LMS MOODLE, which allows to take into account the individual style of each student, organize individual and group learning activities, apply various pedagogical approaches, with a wide range of tools for constructing a training course that includes not only standard modules, but also additional ones, with an unlimited number of installations and the number of users, it is distributed free of charge, etc. Learning Management System (LMS) is an informational platform in the Internet, created to put online educational content and provide communication between the teacher and students, as well as between the students themselves [13].

For the effective and efficient use of LMS MOODLE, according to the results obtained, the authors suggest providing the following pedagogic conditions in IHL: to motivate students value autonomous learning, to train students to work independently in LMS MOODLE, to motivate and educate teachers to implement MOODLE.

The authors have developed a methodology, based on axiological, personal, activity, competency-based and modular approaches, consisting of three stages for the effective formation of learner autonomy with the help of LMS MOODLE, incorporating the content of educational material (six professional modules divided into lexical, grammar and translation parts), consecutive work aimed at the formation and development of autonomous activity skills, realized through tests, questionnaires, polls and a set of exercises (language, preverbal, speech; training exercises and tests), teaching aids (teaching aids, LMS MOODLE):

1) The stage of self-diagnostics: introduction to the subject, gaining access to the LMS MOODLE, motivating students to carry out autonomous activities: tests to determine the initial level of knowledge of a foreign language, setting learning goals, drawing up an individual plan, choosing a strategy for mastering the language;

2) Cognitive and creative stage: students do exercises from the lexical, grammatical and translation modules in accordance with their individual plan; carry out self-monitoring, self-reflection, selfcorrection, self-control. Students' knowledge of the discipline and the ability to work independently are tested. 
3) The stage of evaluation and assessment: assessment of the formation of the components of autonomy with the help of final testing and questionnaires, translator's undergraduate training.

By strategy we understand the means that a user of the language uses to mobilize available resources, enhance skills and abilities in order to successfully accomplish a certain communicative task in the most complete and at the same time economical and accessible way according to the goal [43].

Of all available elements and resources of the LMS MOODLE, in our work the following were used:

- Elements: Poll, Test (for diagnostics), Task, Glossary, Test (types of questions: true / false, short answer, multiple choice, matching, with embedded answers, with a missing word, essay), Forum (for developing a system of exercises).

- Resources: Hyperlink, Book, Page, File (for presentation of the material).

\section{RESULTS}

To prove the efficiency of our methodology we conducted a series of experiments involving $2^{\text {nd }}$ year students at the Academy of Engineering at RUDN University during the $4^{\text {th }}$ semester when they have the 'Introduction to vocationally-oriented translation' course in 2016-2019. We divided the participating students into two groups: the control group (80 students) and the experimental group (70 students) working in MOODLE environment. Before the experiment we tested all the participants to find out the initial level of learner autonomy (questionnaires, surveys, tests, techniques by V. E. Milman, M. Rokich, E.I. Rogov and some others). Their knowledge of English was checked with the test, which includes 52 questions, aimed at assessing the knowledge of lexics, including general scientific vocabulary, grammar, typical for science language, as well as translation skills after completing the basic foreign language course, implying proficiency in a foreign language at level B1. At the stage of self-diagnostics, second-year students demonstrated the following levels of learner autonomy: A (22.65\%), B (42.18\%), C (26,02\%), D (9.15\%).

Thus, the results allow us to draw the following conclusions: at this stage most students have skills necessary for independent work at the productive and creative levels, but there are some students (9.15\%) whose have skills are formed at the factual level. According to the results obtained at the stage of selfdiagnostics, students independently set goals and tasks for autonomous learning on the LMS MOODLE, make an individual work plan - chose 1, 2 or 3 modules for studying and mastering the material, and also determine the strategy of independent mastering a foreign language.

In the middle of the cognitive and creative stage, the students were to answer the questionnaire and be tested by means of the element Test, in which the system randomly selects 50 questions from the question bank on previously completed topics.

The intermediate results showed that $25.31 \%$ of students had learner autonomy formed at the creative level, $41.48 \%$ of students- at the productive level, $28,03 \%$ of respondents - at the reproductive level, and $5.18 \%$ of the participants - at the factual one, which indicates positive dynamics.

At the evaluation and assessment stage, at the end of the semester, formation of learner autonomy components was assessed with the help of the final testing (element Test), which includes 50 questions on vocabulary, grammar and translation skills with different weights from 0.05 points to 1 and questioning.

The results show that the level of learner autonomy of the majority of students is at the creative (32.7\%) and productive $(48.08 \%)$ levels, while no students demonstrated autonomous skills at the factual level.

\section{CONCLUSIONS}

The increase of the quantitative indicators of the proposed criteria for evaluating the individual results of students at each stage of the experimental training allows us to conclude that on completing the course most students have become more autonomous and developed necessary skills for independent work that means that the proposed methodology is effective and efficient for building the learner autonomy and it can be successfully incorporated in training of would-be translators of vocationally-oriented texts.

\section{REFERENCE LIST}

1. Autonomy and independence in language learning (1997) / Edited by Phil Benson and Peter Voller.London and New York: Longman. - 270 p. 
2. Anikina, ZH.S. (2011) Learner autonomy as an integral component of teaching foreign languages in the XXI century. Bulletin of Tomsk State University. № 344. - P. $149-151$

3. Apanovich, E.V. (2003) Methodology of forming learner skills to actuate language material.Candidate thesis, Irkutsk. - 189 p.

4. Benson, P. (2001). Teaching and researching autonomy in language learning. Harlow, Essex, England: Pearson Education Limited.

5. Bezukladnikov, K.E., Kruze, B.A., Vahrusheva, O.V. (2018). Teaching foreign languages to cadets of military school in self-organization environment. Language and culture. - №41. - P.217-240

6. Big psychological encyclopedia / edited by Dubenyuk M. 2007. - Moscow : EHksmo. - 544 p.

7. Biggs J.B. and Moore P.J. The Process of Learning (1993). - New York: Prentice Hall. - 527 p.

8. Chernova O.E., Litvinov A.V., Volkova Z.N., Ivanova M.V., Kogotkova S.S., Ivanova A.G. Developing ESP students' autonomy in Russia: challenges and prospects // EDULEARN17. Proceedings 9th International Conference on Education and New Learning Technologies (Barcelona, Spain, 3-5 July, 2017) Proceedings. - IATED. - 2017. - Pp. 2505-2513.

9.Chernova O., Litvinov A., Ermolova T. Developing autonomy of translators in vocationally-oriented language learning with MOODLE in Russia: approaches, principles, stages, environment //EDULEARN18th Proceedings. 10th Annual International Conference on Education and New Learning Technologies. - 2018. -P. 446-451.

10. Chernova, O., Litvinov A., Goloshumova, G., Telezhko, I., Gakova, E. Electronic information educational environment as a means of learner autonomy development in $\mathrm{IHL}$. Moderl Journal of Language Teaching methods (MJTLM), 2019. Vol. 9, №5.

11. Dickinson L. Self-instruction in language learning (1987). - Cambridge University Press. - 200 p.

12. Federal Law on Education in the Russian Federation № 273-Ф3 of 29.12.2012

13. Gabidulin, A.A. (2016) E-learning platforms and their potential in the educational process exemplified by digital nomads. III international conference Connect Universum 24-26.05.2016 http://connectuniversum.tsu.ru/blog/cuj2015/1059.html (accessed on: 18.06.2017).

13.Gal'skova, N.D. (2004). The theory of teaching foreign languages: language education and methodology. Moscow: publishing center "Academy". - $336 \mathrm{p}$.

14. Gordon W. Allport. The function autonomy of motives (1937).- American Journal of Psychology.Vol.50.- P.141-156.

15. Holec H. Autonomy and Foreign Language Learning (1979).- Pergamon Press. - 53p.

16. Kapaeva, A.E. (2001). On forming learner readiness for self-teaching of foreign languages. Foreign languages at school. - № 3. - P. 12-17.

17.Khodyakov, D.A. (2013) Linguo-didactic model of developing learner autonomy of high-school children. Izvestiya of Volgograd state pedagogical university. - № 5 (80). - P. 85 - 89.

18. Khodyakov, D.A. (2012). Learner autonomy of foreign language students: ability or readiness?] Izvestiya of Volgograd state pedagogical university. - № 10. - P. 98-102.

19. Kolesnikova, I.A. (2003) Basics of andragogy. - Moscow: «Academy». - 240 p.

20.Kovaleva, A.G. (2016) Teaching foreign languages to students of radio engineering specialities on the basis of multimedia transformations. Candidate thesis, Ekaterinburg.- 198 p.

21.Koryakovceva, N.F. (2001) Learner autonomy in learning foreign languages in class activity as educational goal]. Foreign language at school. -№ 1. - P. 13-27.

22.Koryakovceva, N.F. (2001) Learner autonomy in the process of learning foreign languages and culture] In the Proceedings of Autonomy in the practice of teaching foreign languages and culture. - Moscow: MGLU. - P. 12-29.

23.Kulutkin, Y. N. (1985). Psychology for teaching adults. Moscow: Progress.

24. Lier L. Van. (1996) Interaction in the language curriculum. Awareness, autonomy \& authenticity.- Harlow: Longman. $-248 \mathrm{p}$. 
24.Little D. Learner Autonomy (1991). - Dublin. - 154 p.

25.Littlewood, W. (1999). Defining and developing autonomy in East Asian contexts. Applied Linguistics, 20, pp. 71-94.

26.Luksha, I.V. (2008) Language laboratory as a means of learner autonomy optimization in multimedia vocationally-oriented context. Candidate thesis, Tomsk. $-239 \mathrm{p}$.

27.Mariani L. (1997). Teacher support and teacher challenge in promoting learner autonomy. Perspectives, a Journal of TESOL - Italy. - Vol. XXIII, No. 2. - P. 28-36.

28.Nasonova, E.A. (2008) Teaching vocationally-oriented dialogue communication to students in the conditions of learner autonomy by means of internet-chat. Candidate thesis, Volgograd. $-209 p$

29.Nunan, D. (2000). Autonomy in language learning. ASOCOPI 2000. A plenary address.

30. Philip C. Candy (1991). Self-direction for Lifelong Learning, pages $459-466$.

31.Reznickaya, G.I. (2001). Physiological-pedagogical aspects of developing learner autonomy while studying freeing culture. Autonomy in practice of teaching foreign languages and cultures. - № 461. P. 3-5.

32.Simonyan, K.V. (2008) Methodology of applying computer technologies in the organization of self-guided learning. Candidate thesis, Moscow. -213 p.

33.Solovova, E.N. (2004) Learner autonomy as a basis of development of modern life-long personality development. Foreign languages at school. - № 2. - P. 11 - 17.

34.Strelkova, E.V. (2006) Implementation of the concept of learner autonomy in class activity as a means of raising afficiency of the educational process. Proceedings of international scientific conference. - № 8. - P. 67-70.

35.Tambovkina, T.Y. (2007) Self-guided learning of foreign languages as a subsystem of language education in IHLs. Candidate thesis, Moscow. $-150 \mathrm{p}$.

36.Ternovykh, T.Y. (2007). Methodology of forming strategies of learner autonomy in the work with foreign texts. Candidate thesis, Moscow. $-281 \mathrm{p}$.

37.Thong, L.D. (2002) Development of younger children autonomy in class activity. Candidate thesis, Volgograd. $-204 \mathrm{p}$.

38.Trim J. (1990) Learning to learn: investigating learner strategies and learner autonomy Report on Workshop 2A, Uppsala, Sweden. - P.42 -48.

39.Trofimova, I.D. (2003). Methodology of forming strategies of autonomous reading of linguistic university students. Candidate thesis, Ulan-Udeh. $-222 \mathrm{p}$.

40.Tsvetkova, T.K.(2001). Ways of forming learner autonomy in the educational process when teaching foreign languages. Bulletin of MSU. - № 461.- P. $62-72$.

41.Tsyvkunova, E.A. (2002). Formation of learner autonomy of linguistic university on the basis of interdisciplinary interaction of subjects. Candidate thesis, Moscow. -203 p.

42.Ur, P. (1996). A course in language teaching: Practice and theory. Cambridge: Cambridge University Press.

43. Voronin, A.S. (2006). Dictionary of terms of General and Social pedagogy.- Ekaterinburg: UPI University. $-135 \mathrm{p}$. 